\title{
Floating Osteochondroma in the knee joint - A very rare case report
}

\author{
Dr Aditya Pathak ( M.S, D.N.B) ${ }^{1}$,Dr Nataraj B ( D Orth, D.N.B) ${ }^{2}$, \\ Dr Vijay Singh (M.S) ${ }^{3}$,Dr Jain Mikhil (Jr Resident $)^{4}$, \\ Dr Kapane Vijay (D Orth) ${ }^{4}$, \\ 1 Assistant professor-Department of orthopedics, Dr RN cooper Hospital Vile parle west, Mumbai 400056. \\ 2 Senior Divisional Medical officer and Head of Department of Orthopedics, Dr Babasaheb Ambedkar Central \\ Railway Hospital, Byculla, Mumbai - 400027, India. \\ 3 Assistant Divisional Medical officer, Department of Orthopaedics, Dr Babasaheb Ambedkar Central Railway \\ Hospital, Byculla, Mumbai - 400027, India. \\ 4 Junior Residents,Department of Orthopaedics, Dr Babasaheb Ambedkar Central Railway Hospital, Byculla, \\ Mumbai-400027, India.
}

\begin{abstract}
Osteochondroma is the most common benign tumor of bone. It has been seen that this tumor presents itself in various way both clinically and radiologically. Surgical excision is the treatment of choice with less recurrence rates and less chances of malignant transformation. Here is a very unusual presentation of osteochondroma as a solitary loose body within the knee joint in a 45 year male without any other swelling elsewhere in body treated successfully surgically. Such presentation of osteochondroma has not been reported prior to the best of our knowledge.
\end{abstract}

Key words: Intra-articular osteochondroma, loose body.

\section{Introduction}

Osteochondromas are the most frequent benign bone tumors most often found at the metaphyseal or meta-diaphyseal region around the knee joint. ${ }^{1}$ Solitary Osteochondroma in children and adolescent is a common entity and knee joint is a common site. Osteochondroma around knee joint is a known entity but intraarticular is very rare ${ }^{2}$. No sex predilection is reported and age distribution quoted in literature is between 13-65 years. ${ }^{3}$ The presenting symptoms are generally pain (79.1\%), swelling, reduced range of movement, cosmetic abnormalities, bursitis and rarely known to cause pressure symptoms compromising nerve and vasculature. ${ }^{4}$ This case report quotes a very unusual presentation of osteochondroma as an intra-articular tumor that too as loose body in knee joint. Such presentation of osteochondroma has not been reported in literature to the best of our knowledge.

\section{Case Report}

A 43-year-old male manual laborer presented with acute onset left knee pain on any activity since 3-4 days and locking of knee since 1 hour without any history of trauma. Patient had prior 5-6 episodes of locking in past 4 days. Patient also gave history of feeling loose body within the joint. The non-steroid anti-inflammatory drug he had taken for 3-4 days did not relieve his pain. Finally after the knee joint got locked patient presented to us with severe pain

Clinical examination revealed joint line tenderness, swelling, moderate effusion and left knee joint locked in 40 degrees flexion. During Clinical examination while examining the locked knee joint suddenly gave -way getting unlocked and pain was reduced significantly. On radiological investigation a solitary mobile loose body measuring about $2 \mathrm{cms}$ by $2 \mathrm{cms}$ was seen within the knee joint. Considering patients pain and repeated episodes of locking we took patient in emergency operation theatre for removal of foreign body. Examination of other joints and Blood investigations including Serum uric acid, Serum Parathyroid, Serum Calcium and alkaline phosphatase were normal.

Under spinal anesthesia, under all aseptic precaution loose body was first visualized in C-arm. It clearly showed loose body moving within the knee joint freely during motion of the knee. It was then on-table, decided to open the knee joint by an anterolateral approach with mini incision. The loose body was removed using long Kocker forceps Under C-arm Guidance. The bony mass was approximately $2 \mathrm{cms}$ by $2 \mathrm{cms}$ oval shapes with smooth border and one edge being glistening. We expected the loose body to be broken osteophyte but to our surprise the histological examination revealed an osteochondroma consisting of cancellous bone covered with a bony cartilage. Patient had no history of any swelling anywhere in body, no other co-morbid condition, nor any 
such prior episodes.Patient followed up for 1 year and had no symptoms or recurrence with full range of motion of knee joint.

\section{Discussion-}

Intra-articular osteochondroma of the knee is a rare tumor. Generally, osteochondromas occur around the growth plate of long bones in a skeletally immature person and move towards the diaphysis with the connected bone. Therefore, it is rare that osteochondroma is located within the articular compartment of a joint in an adult. Intra-articular osteochondromas of the hip and ankle joint have been reported, these cases are rare. Solitary intra-articular osteochondroma of the knee is an unusual case, which can be successfully managed with arthroscopy. ${ }^{5}$ On the other hand intra-articular osteochondroma is a known occurrence within the knee joint though rare, extra-synovial or intra-synovial in cases of multiple osteochondromatosis. ${ }^{6}$ But intra-articular Solitary osteochondroma that too floating freely within the knee joint in a patient without any other bony swelling elsewhere is a very rare occurrence. In our case report we could not find the origin of the osteochondroma.

Skeletal osteochondroma is a developmental lesion, rather than a true neoplasm, and is also known as osteocartilaginous exostosis and its x-ray features are usually diagnostic, demonstrating lesion composed of cortical and medullary bone with an overlying hyaline cartilage cap, with continuity of underlying parent bone. However, an osteochondral neoplasm of the soft tissue, which is a lesion of uncertain pathogenesis, is uncommon and usually arises from the synovial tissue in joints and tendon sheaths or bursa in the hands and feet. Extraskeletal osteochondromas may arise rarely outside of synovial compartments such as that from infrapatellar fat pad. ${ }^{7}$ But in our case report neither the clinical presentation nor the X-ray features were suggestive of Osteochondroma.

Osteochondromas are osseous outgrowths arising from the bony cortex with enchondral ossification. These tumors arise mainly in tubular bones near the metaphyses. ${ }^{8}$. Metaplastic proliferation of the connective tissue of the joint capsule or of the tissue adjacent to the capsule, which includes collagen, fat, lymph channels, nerves, synovial lining and blood vessels, is believed to be the origin of the intracapsular or para-articular chondromas and osteochondromas. The lesions have been reported as capsular osteochondromas, extraskeletal osteochondromas, ossifying chondromas, intracapsular or para-articular chondromas, and soft tissue chondromas. The most common differential diagnosis for these lesions are detached osteophytes, osteochondritis dessicans, osteochondral fractures, synovial chondromatosis, low-grade chondrosarcoma, and osteosarcoma, so in some cases a biopsy should be performed before excising the tumor.MRI imaging helps to differentiate these lesions ${ }^{9}$. Distinguishing osteochondromas from synovial chondromatosis is based on the proliferation of multiple nodules of hyaline cartilage in the connective tissue lining the synovial membrane of a large joint. Chondromatosis also has a diffuse growth pattern and a subsynovial location. Chondrosarcoma is usually due to transformation of an osteochondroma; about $1 \%$ are solitary lesions and $20 \%$ are hereditary multiple exostoses. It occurs as a primary cartilaginous lesion. Extraosseous chondrosarcoma is uncommon, it tends to be larger than an osteochondroma, and it shows secondary bony involvement. The method for measuring the thickness of the cartilage cap is important in differentiating osteochondromas from exostotic chondrosarcomas, both preoperatively and postoperatively. ${ }^{10}$ Our case report showed on biopsy an osseous type of osteochondroma with cartilage cap suggestive of benign nature. Patient had no history of swelling elsewhere, neither trauma nor any synovial swelling with multiple loose bodies.

Intra-articular osteo-chondroma presenting as loose body floating within the knee joint have been reported as a very rare occurrence but that too in cases of hereditary multiple osteochondromatosis . A surgical removal, preferably by arthroscope is a useful technique to deal with such intra-articular osteochondromas. ${ }^{11}$ Our patient post-operative had completed range of motion with no pain or locking of the knee joint with a good follow up of 1 year.

To conclude we would only like to say that there are indeed multiple forms of in which osteochondroma can present one of which - as a loose body floating within the knee joint solitary swelling and excision surgically by arthroscopic ( preferred) or open method is treatment of choice with less recurrence rated and good prognosis.

\section{Figure Legends-}

Figure 1-

A) and B) Antero-posterior and lateral views pre-operative showing Floating loose body - osteochondroma, C) and D) Antero-posterior and lateral views post-operative at 1year follow up showing no recurrence.

Figure 2

A) Immediate post operative image of knee joint with incision sutured .B) and C) showing intra-operative images of operated knee joint and excised osteochondroma. 
Figure 3 -

A) and B) showing histopathology slides of osteochondroma with bone matrix and cartilage cap. C) and D) Electronic images of osteochondroma.

\section{Conflict of Interest-}

NONE.

\section{Acknowledgements -}

NONE.

Figures -

Figure 1 -
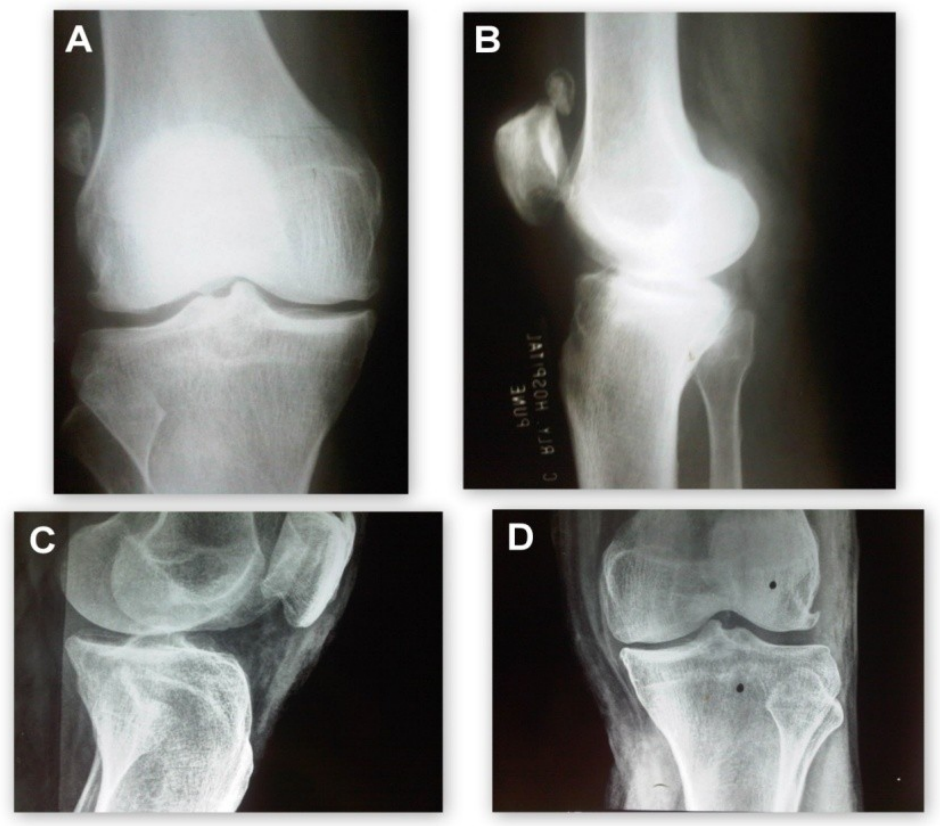

Figure 2-
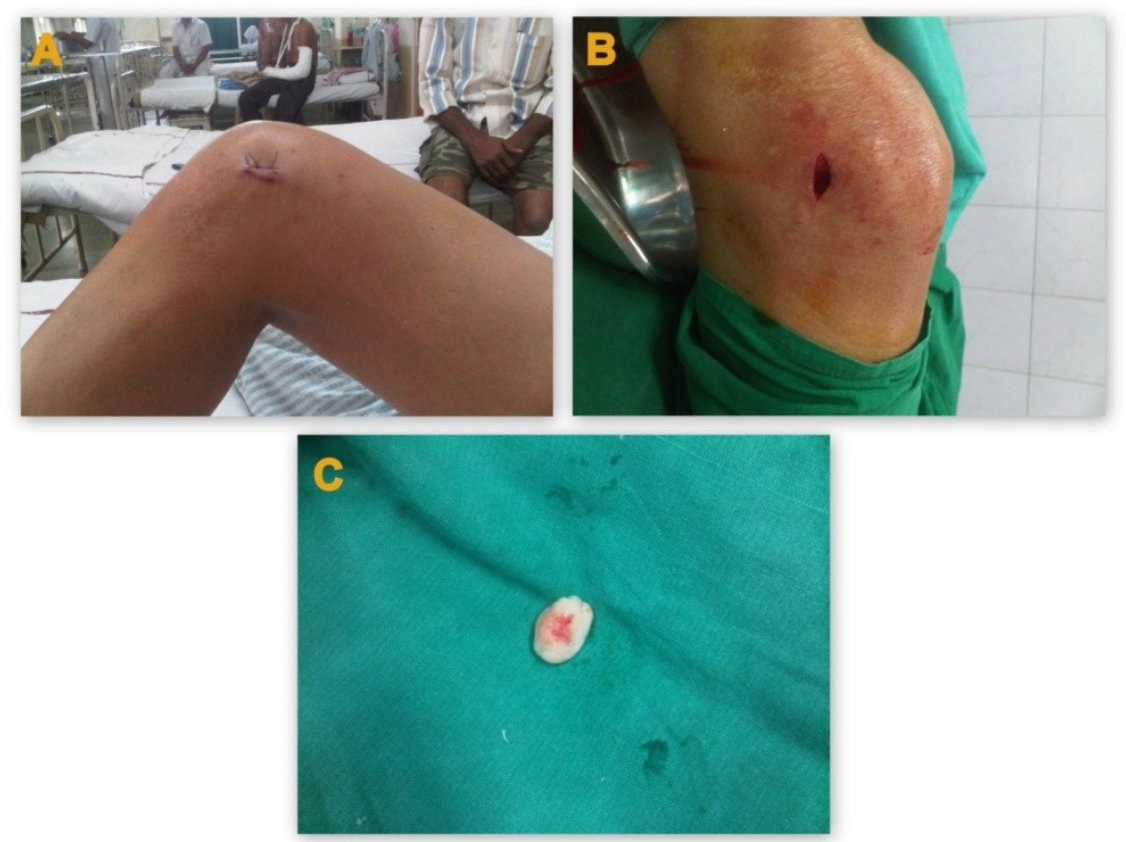
Figure 3-
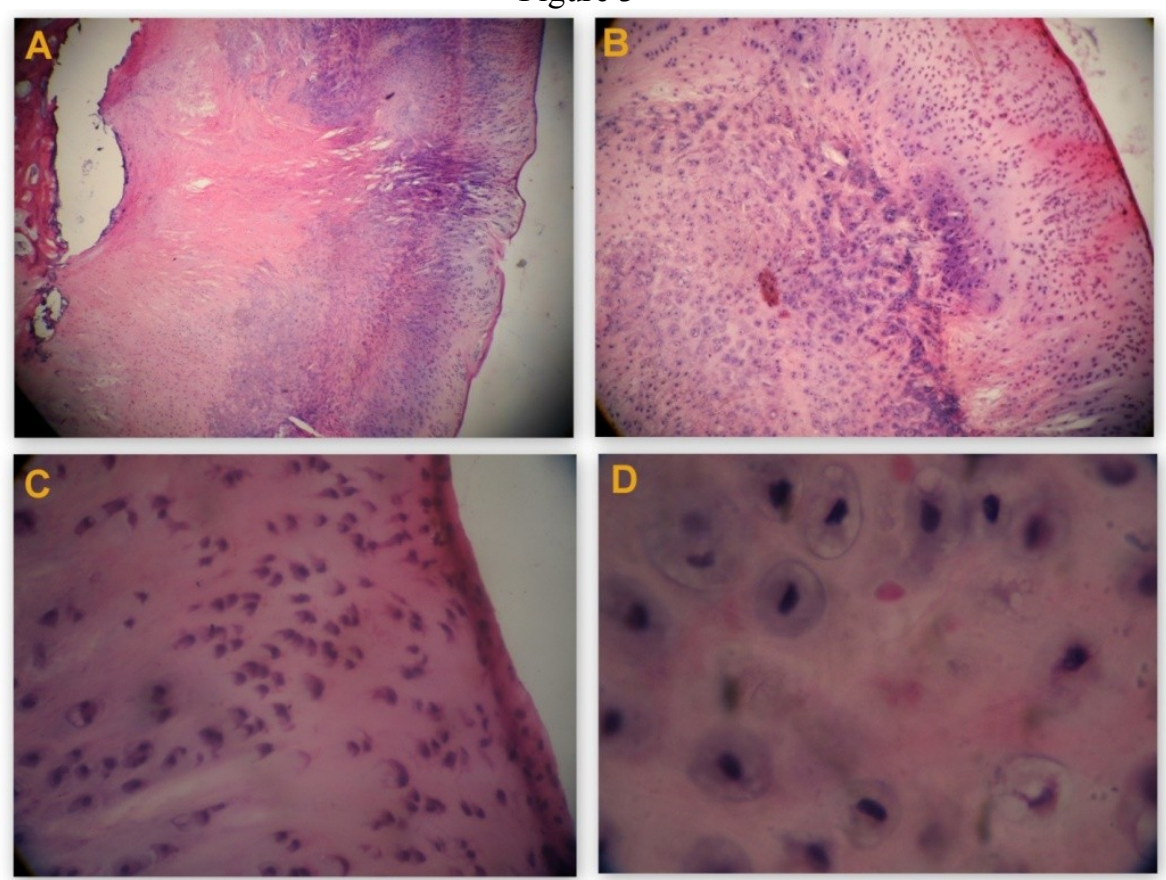

\section{References}

[1]. Taneda Y, Nakamura K, Yano M, et al. Popliteal artery aneurysm caused by osteochondroma. Ann Vasc Surg 2004; 18:121-123.

[2]. Ogura K, Gotu T, Nemoto T, Imanishi J- “ Para-articular osteochondroma of the infrapatellar fat pad. J knee surg, 2011;24:209-13.

[3]. Chen HH, Huang GS, Lee JH, Chou TY. Soft tissue condroma: case report. Chung Hua I Hsueh Tsa Chih (Taipei) 1991;48:397-399.

[4]. F. BOTTNER, R. RODL, I. KORDISH, W. WINKLEMANN, G. GOSHEGER, N. LINDNER - " Surgical treatment of symptomatic osteochondroma- 3-8 years follow-up study.J Bone Joint Surg [Br] 2003;85-B:1161-5.

[5]. Jong In Kim, Jae Ho Kwon, Yong Lee Park et al- Arthroscopic Excision of Solitary Intra-articular Osteochondroma of the Knee. Knee Surg Relat Res. 2013 March; 25(1): 36-39.

[6]. Takahashi M, Nishihara A, Ohishi T et al -Arthroscopic resection of an intra-articular osteochondroma of the knee in the patient with multiple osteochondromatosis. Arthroscopy. 2004 Jul;20 Suppl 2:28-31.

[7]. Demir M, Unlu E, Usta U- A curious mass of anterior compartment of knee- The British Journal of Radiology, 82 (2009), 435-437

[8]. Argin M, Arkun R, Parildar M, Selen B- Solitary osteochondroma causing popliteal pseudoaneurysm that presented as a mass lesion.Diagn Interv Radiol 2007; 13:190-192

[9]. De Maio F, Potenza V, Farsetti p et al- Giant intra-articular, extra-synovial osteochondroma of Knee- a report of two cases.The Open Orthopaedics Journal, 2011, 5, 368-371

[10]. Huang G, Hung J,Pen Y et al- Fat pad osteochondroma of knee-J Med Sci 2005;25(6):315-318

[11]. Matsuda S, Oda Y, Matsumoto Y et al- Intra-articular osteochondroma of knee in patient of Hereditary multiple osteochondromatosis. Fukuoka acta med,2007,98(12)425-430 